Check for updates

Cite this: RSC Adv., 2017, 7, 41070

Received 4th June 2017

Accepted 31st July 2017

DOI: $10.1039 / c 7 r a 06230 c$

rsc.li/rsc-advances

\title{
A novel cellulose-silicalite-1 membrane with excellent gas separation property
}

\begin{abstract}
Xin-ling Fu, (D) Ming Zeng, Jian-bo Zhou* and Chao Xu*
A novel strategy for synthesizing silicalite-1 membrane by hydrothermal synthesis without organic template after coating the support with a mixture of modified cellulose and seeds was successfully proposed. The membrane possesses high ideal separation factors of $\mathrm{H}_{2}$ over various gases which is larger than the corresponding Knudsen diffusion coefficients. The selectivity of AcOH from AcOH/ $\mathrm{H}_{2} \mathrm{O}$ mixtures can reach to 65 and stable for $180 \mathrm{~h}$. The characterization results by XRD and SEM showed that the excellent performance can be attributed to both modified cellulose and the synthesis without organic template. Modified cellulose attracted more silicalite-1 nutrients to the support and assisted the synthesis of more compact silicalite-1 zeolite membrane. Calcination after synthesis was avoided, thus avoiding macrostructure defects appearing during the process of calcination.
\end{abstract}

\section{Introduction}

Membrane separations have made significant contributions in fuels, petrochemicals, energy, and renewable chemical sectors because of their excellent properties, such as energy efficiency, low cost and environment friendliness, compared with conventional separation methods. ${ }^{1}$ Inorganic zeolite membranes are effective in gas and liquid separations because they present some substantial advantages over conventional organic materials with respect to thermal and chemical stabilities. ${ }^{2,3}$ Recently, much study has been reported on preparation and separation application of molecular-sieve inorganic zeolite membranes. ${ }^{4,5}$ Despite great advances in zeolite membrane separation technology, particularly with respect to alcoholwater separation, ${ }^{6}$ formation of compact and thin films for gas separation is still favored.

Various methods have been explored by researchers to synthesize zeolite membranes such as direct hydrothermal crystallization, ${ }^{7}$ adding seeds ${ }^{8,9}$ or organic cations, ${ }^{10,11}$ microwave heating ${ }^{12}$ and gas-phase transformation. ${ }^{13}$ The organic templates, which are required for the formation of the zeolite crystal structure, are used in most processes of synthesizing zeolite membranes. Accordingly, heat treatment after hydrothermal synthesis is a common post-treatment of zeolite membranes for removing SDAs and/or water from the zeolite pores. However, the zeolite membranes are easy to crack due to the mismatches in the thermal expansion coefficients between support and zeolite layer. While some MFI-type zeolite

Department of Anatomy, Histology and Embryology, College of Basic Medical Sciences, Changsha Medical University, Changsha, Hunan 410219, China. E-mail: fuxinling220@126.com membranes with high performance after calcining at high temperatures have been reported, ${ }^{14}$ several studies have also shown that during the calcination process, micro cracks tend to form in the zeolite membranes due to thermal stress caused due to the difference in thermal expansion coefficients between the zeolite layer and support and/or resulting from the changes in lattice parameters of zeolite crystals as a consequence of the removal of templates. ${ }^{15,16}$ Recently, Choi et al. ${ }^{17}$ developed a rapid thermal processing (RTP) method to avoid the formation of such defects, possibly by strengthening grain bonding at the grain boundaries. While an appreciably high separation performance could be achieved, this method is complicated and expensive, which confines the practical applications. Accordingly, a new method to obtain high-performance zeolite membrane with few cracks is still a great challenge. Based on this consideration, coating a modified layer between the zeolite layer and support, which not only eliminates the grain boundary defects caused by the mismatch of thermal expansion coefficients between the support and zeolite layer but also attracts more active components to the support, and then synthesizing a zeolite layer without organic template to avoid calcination at high temperature appears to be a better approach.

In this study, a novel strategy for synthesizing silicalite-1 zeolite membrane is explored, namely, by modifying the support with modified cellulose and carrying out hydrothermal synthesis without organic template. The crystals that grow on the surfaces of the alumina supports are smooth and dense. The continuous zeolite top layer of the membrane was analyzed via scanning electron microscopy (SEM) and checked via gas permeation measurements and separation of acetic acid-water mixtures, and X-ray diffraction (XRD) was employed to examine 
the crystal structure of the prepared membranes. This study introduces new approaches for the improvement of separation performances of zeolite membranes in the field of membrane synthesis.

\section{Experimental}

\subsection{Materials}

All the chemicals, including tetrapropylammonium hydroxide (TPAOH) (Analytical Reagent, Aladdin), sodium hydroxide (Analytical Reagent, Guangzhou), colloidal silica solution (30 wt\%, Guangzhou), dimethyl sulfoxide (DMSO) (Analytical Reagent, Guangzhou), paraformaldehyde (PF) (Analytical Reagent, Guangzhou), and $\alpha$-cellulose (Analytical Reagent, Aladdin), were used as purchased without purification.

\subsection{Synthesis of silicalite-1 zeolite seeds}

Silicalite-1 zeolite seeds were synthesized via hydrothermal heating. The solution was prepared by mixing $0.3 \mathrm{~g}$ sodium hydroxide, $16 \mathrm{~g}$ colloidal silica solution and $25 \mathrm{~mL} 1 \mathrm{~mol} \mathrm{~L}^{-1}$ TPAOH in deionized water under vigorous stirring. After aging for $12 \mathrm{~h}$ at $25{ }^{\circ} \mathrm{C}$, the solution was hydrothermally treated in a Teflon lined stainless steel autoclave at $120{ }^{\circ} \mathrm{C}$ for $12 \mathrm{~h}$. The seed powder obtained by centrifugation was washed with distilled water until pH 7 and dried at a temperature of $100^{\circ} \mathrm{C}$. The organic template TPAOH was removed by calcining at $450{ }^{\circ} \mathrm{C}$ for $8 \mathrm{~h}$ with a heating rate of $1{ }^{\circ} \mathrm{C} \mathrm{min}{ }^{-1}$. The as-obtained silicalite-1 zeolite powders, named as $\mathrm{S} 1$, were subjected to characterization. As a comparison, silicalite-1 zeolite powders in the market, named as S2, were also characterized.

The appropriate sample was screened as the seed by characterizing the types of powders.

\subsection{Preparation of seed suspension}

Modified cellulose solution was prepared according to the following procedure: (1) $4 \mathrm{~g} \alpha$-cellulose and $20 \mathrm{~g}$ DMSO were mixed and put into a Teflon lined stainless steel autoclave at $60{ }^{\circ} \mathrm{C}$ for $30 \mathrm{~min}$. (2) Opening the cover of the autoclave, $4 \mathrm{~g}$ PF and $20 \mathrm{~g}$ DMSO were added into it and the cover was closed. (3) The autoclave was put in a furnace of $120^{\circ} \mathrm{C}$ for $24 \mathrm{~h}$. (4) A clear liquid was obtained by centrifugation with the rotation rate of $6000 \mathrm{rpm}$ twice, each time for $5 \mathrm{~min}$.

Moreover, $0.2 \mathrm{~g}$ silicalite- 1 seed crystal powder was added into the modified cellulose solution and subsequently dispersed in an ultrasonic bath for $20 \mathrm{~min}$. Thus, the welldispersed silicalite-1 seeds suspension was obtained with a ratio solid/liquid $=5 \mathrm{~g} / 1000 \mathrm{~g}$. Moreover, the same concentration of seed suspension without cellulose was prepared by adding silicalite-1 zeolite into DMSO. Both the suspension solutions were degassed in vacuum to avoid the formation of voids between the polymer and zeolite phases resulting from the air adsorbed on the surface of the zeolite particles.

\subsection{Introduction of zeolite seeds to support}

A home-made porous $\alpha-\mathrm{A1}_{2} \mathrm{O}_{3}$ disc, with diameter of $22 \mathrm{~mm}$, thickness of $1.8 \mathrm{~mm}$, porosity of $65 \%$, and average pore size of
$300 \mathrm{~nm}$, was used as support for the growth of zeolite membrane. The $\alpha-\mathrm{A}_{2} \mathrm{O}_{3}$ disc was polished with grit-sand paper, followed by washing with $1 \mathrm{~mol} \mathrm{~L}^{-1}$ sodium hydroxide solution before using as a support. The support was dried at $110^{\circ} \mathrm{C}$ after being cleaned with deionized water in an ultrasonic cleaner and subjected to the loading of silicalite-1 zeolite seeds without cooling.

In order to form a homogeneous seed layer, hot dip-coating method $^{18}$ was employed to deposit zeolite seeds on the surface of the support. The hot support disc was dipped in the silicalite1 seed suspensions and maintained for $10 \mathrm{~s}$ to allow the seed crystals to be adsorbed on the surface and then gently slid and pulled up from the seeds suspension. Finally, it was dried at $110{ }^{\circ} \mathrm{C}$ in vacuum for $1 \mathrm{~h}$. This was repeated three times to obtain a uniform distribution of seed particles on one side of the support.

\subsection{Synthesis of silicalite-1 zeolite membrane}

The solution for the synthesis of silicalite- 1 membrane was prepared by mixing $0.74 \mathrm{~g}$ sodium hydroxide, $16 \mathrm{~g}$ colloidal silica solution and $41.5 \mathrm{~g}$ deionized water under vigorous stirring. The solution was boiled until it became clear and then aged for 1 day.

Silicalite-1 membrane was synthesized via hydrothermal heating. The seeded support disc was first vertically immerged in the synthesis solution contained in a Teflon reactor and then the reactor was transferred into a preheated oven at $180{ }^{\circ} \mathrm{C}$ for $24 \mathrm{~h}$. After cooling to room temperature, the disc was removed from the autoclave and washed with distilled water in an ultrasonic bath for $10 \mathrm{~min}$. Finally, the disc was washed repeatedly by deionized water till neutral and dried first at $35^{\circ} \mathrm{C}$ for $3 \mathrm{~h}$ and then at $100{ }^{\circ} \mathrm{C}$ overnight. The as-obtained silicalite- 1 membrane was further subjected to a secondary synthesis with the same method mentioned above but reacted just for $8 \mathrm{~h}$.

The membrane seeded without modified cellulose was named as M1, while the membrane seeded with modified cellulose was named as M2.

\subsection{Characterization of silicalite-1 zeolite membrane}

The structure of the membranes was examined via X-ray diffraction (XRD) (Bruker D8) with a scanning voltage of $40 \mathrm{kV}$, scanning current $40 \mathrm{Ma}$ and scanning step $0.02^{\circ}$. The morphology and thickness of the silicalite- 1 membranes were confirmed via scanning electron microscopy (SEM) (FEI Quanta200) with an accelerating voltage of $20 \mathrm{kV}$. The contact angles of the silicalite-1 membranes were measured with contact angle analyzer (WCA) (DSA100).

\subsection{Performance of silicalite-1 membranes}

The performance of silicalite- 1 zeolite membrane was manifested by gas permeation and pervaporation. They were carried out over self-designed equipment, which was similar to that reported in literature. ${ }^{19}$

2.7.1 Gas permeation. The disc was sealed in the permeation cell with the membrane layer on the high-pressure side. Single gas $\left(\mathrm{H}_{2}\right.$ with $\mathrm{CO}, \mathrm{CO}_{2}, \mathrm{~N}_{2}, \mathrm{CH}_{4}$ and $\left.\mathrm{C}_{3} \mathrm{H}_{8}\right)$ permeated 
through the membrane, and permeated flux was measured by a soap-film flow meter. The permeance $(J)$ and ideal selectivity for $\mathrm{H}_{2}$ over other gases were respectively calculated according to eqn (1) and (2):

$$
\begin{gathered}
J\left(\mathrm{~mol} \mathrm{~m} \mathrm{~m}^{-2} \mathrm{~s}^{-1} \mathrm{~Pa}^{-1}\right)=\frac{n}{S t \Delta p} \\
\alpha_{\mathrm{A} / \mathrm{B}}=\frac{J_{\mathrm{A}}}{J_{\mathrm{B}}}
\end{gathered}
$$

where $n, \Delta p, S, t, \mathrm{~A}$ and $\mathrm{B}$ are the moles of permeated gas, the pressure difference between two sides of zeolite membrane, the permeating area of zeolite membrane, the permeating time, $\mathrm{H}_{2}$ and other gases $\left(\mathrm{N}_{2}, \mathrm{CO}, \mathrm{CO}_{2}\right.$ and $\left.\mathrm{C}_{3} \mathrm{H}_{8}\right)$, respectively.

2.7.2 Pervaporation. The zeolite membrane was characterized by pervaporation of $10 \mathrm{wt} \%$ acetic acid-water mixture at $70{ }^{\circ} \mathrm{C}$. The measurement pressure was $0.4 \mathrm{MPa}$, and the permeate area was $1.54 \times 10^{-6} \mathrm{~m}^{2}$. The permeate side remained in a vacuum state, and a cold trap in liquid $\mathrm{N}_{2}$ was used to collect the permeate. The compositions of both feed and the permeate were measured via chromatography (SP-6890). The pervaporation separation factor is calculated according to eqn (3):

$$
\alpha_{\mathrm{A}, \mathrm{B}}^{*}=\frac{y_{\mathrm{A}} / y_{\mathrm{B}}}{x_{\mathrm{A}} / x_{\mathrm{B}}}
$$

where $y_{\mathrm{A}}$ and $y_{\mathrm{B}}$ are the weight fractions of acetic acid and water in the permeate, respectively, and $x_{\mathrm{A}}$ and $x_{\mathrm{B}}$ are their corresponding weight fractions in the feed.

\section{Results and discussion}

\subsection{Characterization of silicalite-1 seeds}

Fig. 1 shows the XRD patterns of silicalite- 1 powders of S1 and $\mathrm{S} 2$. From the figure, one can see that the XRD patterns of both S1 and S2 are well consistent with the JCPDS file \#44-0696 without diffraction peaks from other crystals, indicating a pure phase of silicalite-1 zeolite. However, the XRD peaks of S1 exhibit smaller peak intensity and larger peak width than that of $\mathrm{S} 2$, indicating that the crystal size of $\mathrm{S} 1$ is smaller than that for

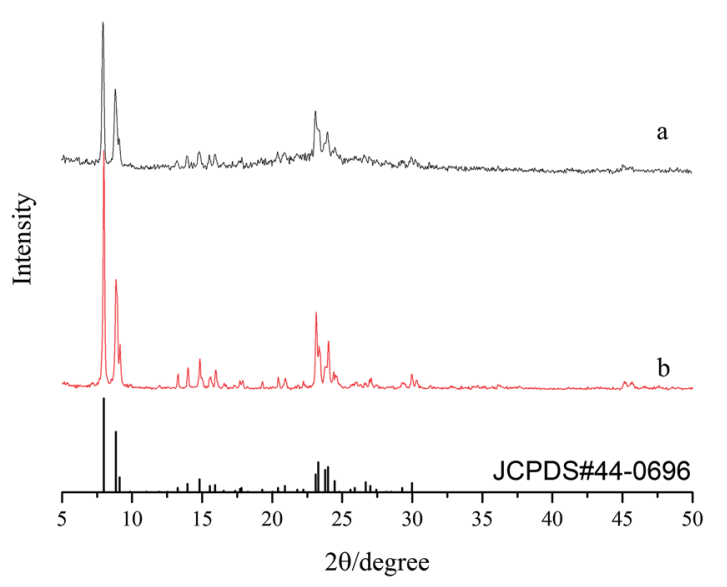

Fig. 1 XRD patterns of (a) S1 and (b) S2.
S2. ${ }^{20}$ In order to determine the crystal size of both S1 and S2, the corresponding SEM has been shown in Fig. 2. It is found that the morphology of S2 shows hexagonal prism type with clear edges and the corresponding average crystal size is $c a .6 \mu \mathrm{m}$, while $\mathrm{S} 1$ possesses a reduced crystal size, being determined as ca. $0.3-1 \mu \mathrm{m}$, with few lattice defects. It is reported that smaller crystal size and more defective surface could induce denser membrane layer. ${ }^{21}$ Accordingly, the powders of S1 have been used as the seeds for the further growth of silicalite- 1 zeolite membrane.

\subsection{Characterization of silicalite-1 zeolite membranes}

Fig. 3 shows the XRD patterns of various silicalite- 1 zeolite membranes. One can see that the sharp peaks at $2 \theta=25.76^{\circ}$, $35.34^{\circ}, 37.96^{\circ}$ and $43.55^{\circ}$ can be attributed to $\alpha-\mathrm{Al}_{2} \mathrm{O}_{3}$ support, and the peak intensity for $\alpha-\mathrm{A}_{2} \mathrm{O}_{3}$ decreases after zeolite membrane is synthesized. After seeding, the characteristic diffraction peaks of silicalite- 1 zeolite at $2 \theta=8.22^{\circ}, 9.08^{\circ}$ and $23.50^{\circ}$ appear in the support seeded without cellulose, while in addition to silicalite- 1 characteristic diffraction peaks, a broad peak from $15^{\circ}$ to $23^{\circ}$ also appears in the support seeded with cellulose. The broad peak can be attributed to the diffraction peak of modified cellulose, indicating that cellulose carrying the hydroxyl functional group is also uniformly dispersed on the surface of the support. After the synthesis, the peak intensity for silicalite-1 zeolite increases and that for $\alpha$ - $\mathrm{A}_{2} \mathrm{O}_{3}$ decreases. It should be addressed that the peak intensities of silicalite- 1 zeolite, particularly those of the peaks at $2 \theta=8.22^{\circ}, 9.08^{\circ}$ (see the circle shown in Fig. 3), are higher for M2 membrane than that for M1 membrane, indicating that the silicalite-1 zeolite layer is thicker or compacter over the former membrane relative to the latter membrane.

Fig. 4 shows the SEM micrographs of various silicalite-1 zeolite membranes. From the top view of the micrographs (Fig. 4a and c), one can see that the coffin-shape grains of silicalite- 1 crystals gather together over the support and construct a continuous zeolite layer for all the membranes. However, the crystal particles randomly deposit on the support and numerous defects are formed between zeolite grains in M1 membrane. As a striking contrast, the crystals deposit on the support existing in the form of twins and no significant defect can be identified in M2 membrane. The cross sectional view of the micrographs (Fig. 4b and d) show that a silicalite-1 zeolite layer has tightly grown over the support without any evident pinholes. However, the thickness of the zeolite layer is thicker for M2 membrane than that for M1 membrane, being identified as $5 \mu \mathrm{m}$ and $2.8 \mu \mathrm{m}$, respectively. These results are consistent with the results of XRD. Fig. 5 shows the apparent contact angles of silicalite- 1 zeolite membrane. One can see that, $\alpha-\mathrm{A}_{2} \mathrm{O}_{3}$ support is completely hydrophilic and the corresponding contact angle is approximately $0^{\circ}$. After the hydrothermal synthesis, the contact angle increases. The contact angle of M1 membrane is $43^{\circ}$, while that of M2 membrane is $61^{\circ}$.

The above mentioned results can be attributed to the fact that the modified cellulose layer is between the support and zeolite layer. In DMSO solvent, PF reacts with cellulose to 

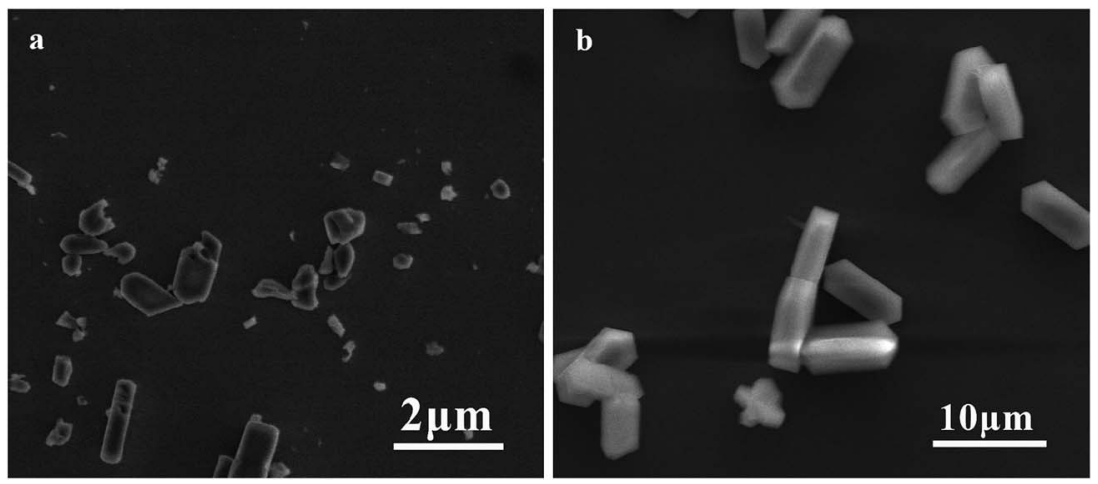

Fig. 2 SEM micrographs of silicalite-1 powders: (a) S1 and (b) S2.

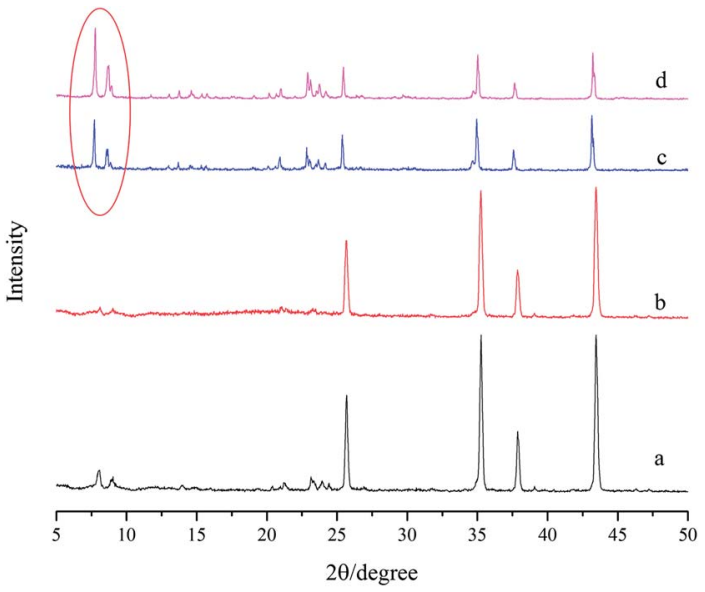

Fig. 3 XRD patterns of (a) seed layer without modified cellulose; (b) seed layer with modified cellulose; (c) M1 membrane and (d) M2 membrane.

produce cell-O- $\mathrm{CH}_{2}-\mathrm{OH},{ }^{22}$ making more - $\mathrm{OH}$ group exposed to the solution, and when the support, which is coated with modified cellulose, is in contact with the synthetic solution, hydrogen bond is formed between -OH groups of modified cellulose and silanol groups of the precursor macromolecules of silicalite-1. Due to those high efficient molecular links between cellulose and silicalite-1 nutrients, more silicalite-1 nutrients are adsorbed on the surface of the support and easily grow to a dense and continuous silicalite- 1 zeolite membrane. Moreover, there is no templating agent in the process of synthesizing the silicalite- 1 zeolite membrane, thus avoiding the destruction of the zeolite layer during the calcination process. It should be addressed that silicalite- 1 zeolite membranes have a certain hydrophobicity and the hydrophobicity becomes stronger when the zeolite membrane is denser.

\subsection{Performance of silicalite-1 membranes}

The performance of various small molecule gases through M1 and M2 membranes are shown in Fig. 6. One can see that the permeations of various gases through M1 membrane are higher than that for M2 membrane, but the permeances are at a level of $10^{-7}$ to $10^{-6} \mathrm{~mol} \mathrm{~m}{ }^{-2} \mathrm{~s}^{-1} \mathrm{~Pa}^{-1}$. Both membranes show that gases with smaller kinetic diameter, except for $\mathrm{CO}_{2}$, have higher permeation flux, and the permeance of $\mathrm{H}_{2}$ is the highest. The lower permeation flux of $\mathrm{CO}_{2}$ can be due to the fact that $\mathrm{CO}_{2}$ is
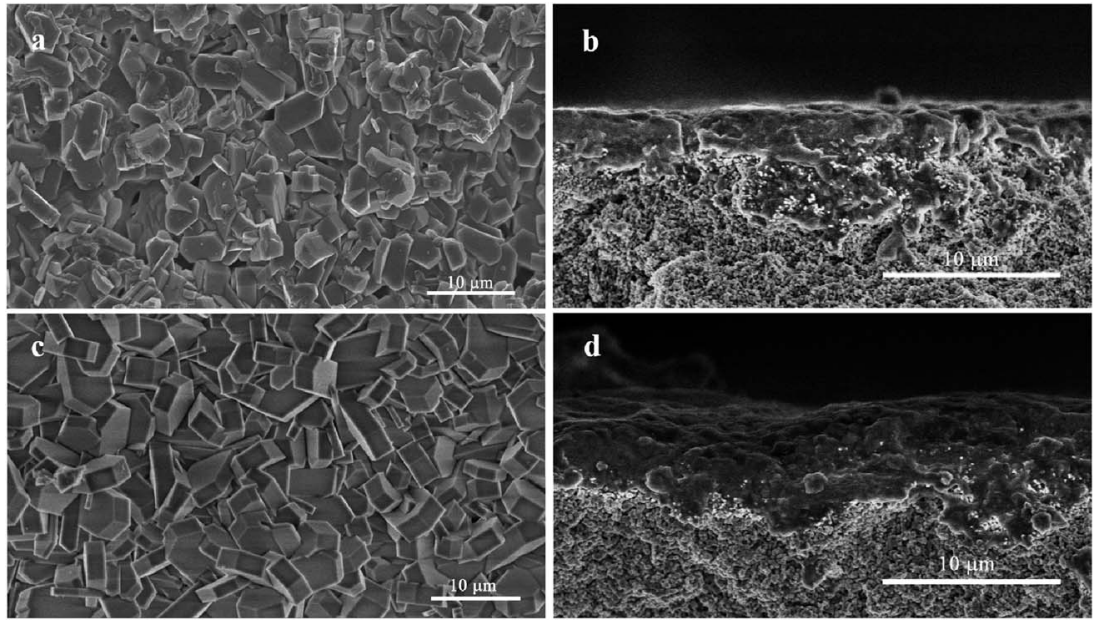

Fig. 4 SEM micrographs of silicalite-1 zeolite membranes. (a) and (c), top view for M1 and M2 membranes, respectively; (b) and (d), crosssectional view for $\mathrm{M} 1$ and $\mathrm{M} 2$ membranes, respectively. 
a

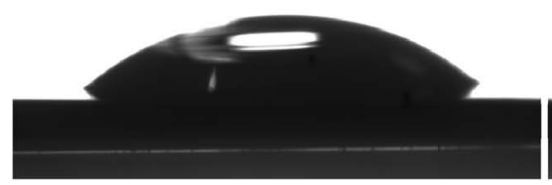

$43^{\circ}$ b

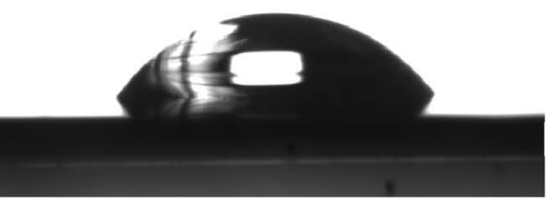

Fig. 5 The apparent contact angles of silicalite-1 zeolite membranes. (a) M1 membrane; (b) M2 membrane.

more condensed and adsorbed in the pores of zeolite. ${ }^{23}$ The ideal separation factors of $\mathrm{H}_{2}$ over various gases through both M1 and M2 membrane are shown in the upper right corner of Fig. 6. The ideal separators of $\mathrm{H}_{2}$ over various gases through M2 membrane are higher than that for the corresponding Knudsen diffusion coefficients, even higher than that through M1 membrane, which are determined as 5.10, 4.24, 4.25, 4.27 and 5.55 for $\alpha\left(\mathrm{H}_{2} / \mathrm{CO}_{2}\right), \alpha\left(\mathrm{H}_{2} / \mathrm{N}_{2}\right), \alpha\left(\mathrm{H}_{2} / \mathrm{CO}\right), \alpha\left(\mathrm{H}_{2} / \mathrm{CH}_{4}\right)$ and $\alpha\left(\mathrm{H}_{2} / \mathrm{C}_{3} \mathrm{H}_{8}\right)$, respectively. This occurrence can be due to the compactness of the zeolite membrane. M1 membrane is thin with numerous defects in macroporous structures; and hence it is easy for all the gases to pass through the membrane with low selectivity. In comparison, M2 membrane is denser with few defects, and the gases pass through the membrane from the pores of zeolite. The gas with small kinetic diameter will be preferred through the pores of the zeolite, while the gas with larger kinetic diameter will be blocked by the membrane. Accordingly, M2 membrane shows higher selectivity than M1 membrane and the corresponding Knudsen diffusion coefficients.

Silicalite-1 membrane is a hydrophobic zeolite membrane (see Fig. 5). When organic aqueous solutions are fed in the membrane, organics are preferably adsorbed on the surface of zeolite membrane and passed through the pores of zeolite. Accordingly, silicalite-1 membrane has a good separation effect on acetic acid aqueous solution. Fig. 7 shows $\mathrm{AcOH} / \mathrm{H}_{2} \mathrm{O}$ separation factors of $\mathrm{M} 1$ and $\mathrm{M} 2$ membranes at $70{ }^{\circ} \mathrm{C}$ and under 0.4 MPa pressure difference. One can see that M2 membrane exhibits higher selectivity towards water separation than M1 membrane, and the separation factor of $\mathrm{AcOH}$ over water through M2 membrane can reach up to 65. Moreover, M2 membrane still remains highly stable after $180 \mathrm{~h}$, while the separation factor of M1 membrane begins to drop linearly after 50 h. Furthermore, Fig. 8 shows SEM micrographs of silicalite-1 zeolite membranes after treating with $\mathrm{AcOH} / \mathrm{H}_{2} \mathrm{O}$ mixture for $180 \mathrm{~h}$. One can see that both M1 and M2 membranes are still covered with coffin-shaped grains of silicalite-1 crystals. However, the edges of the crystals are blurred and a large number of holes appear on the surface of M1 membrane. This result is because there is no calcination, and some amount of silanol group on the surface of zeolite membrane is retained. Those silanol groups form a dense network via hydrogen bond and few silanol groups are exposed to the outside of the membrane. Therefore, water molecules are difficult to adsorb on the surface of the zeolite membrane, while $\mathrm{AcOH}$ molecules are preferentially adsorbed on it. M2 membrane with dense

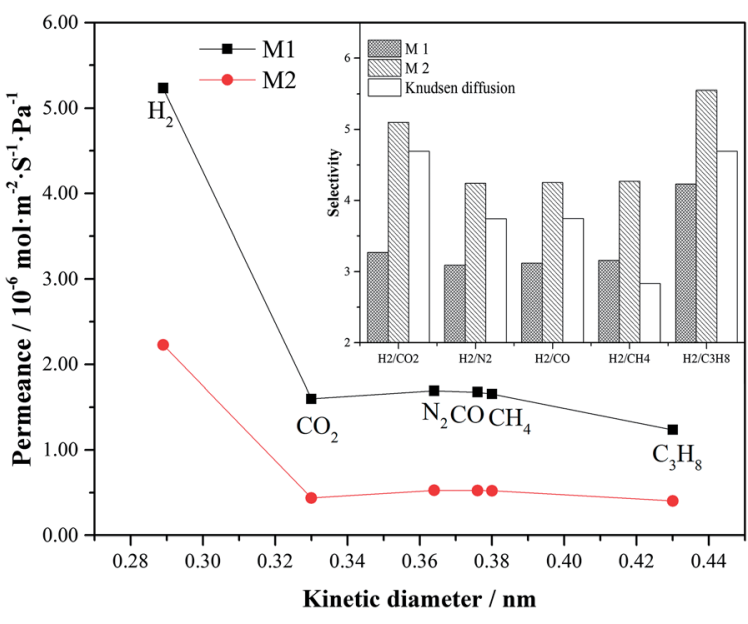

Fig. 6 Performance of various small molecule gases through M1 and M2 membranes at $298 \mathrm{~K}$ and under 0.1 MPa pressure difference.

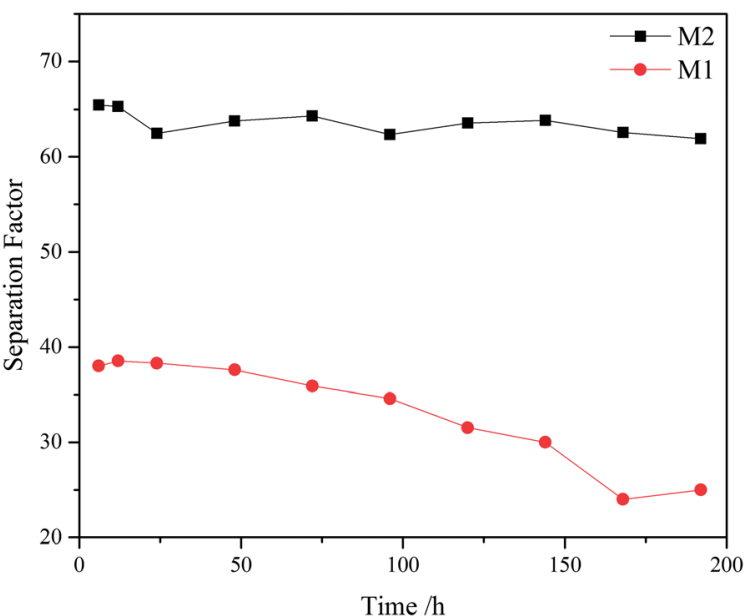

Fig. $7 \mathrm{AcOH} / \mathrm{H}_{2} \mathrm{O}$ separation factors of $\mathrm{M} 1$ and $\mathrm{M} 2$ membranes at $70{ }^{\circ} \mathrm{C}$ and under 0.4 $\mathrm{MPa}$ pressure difference. 


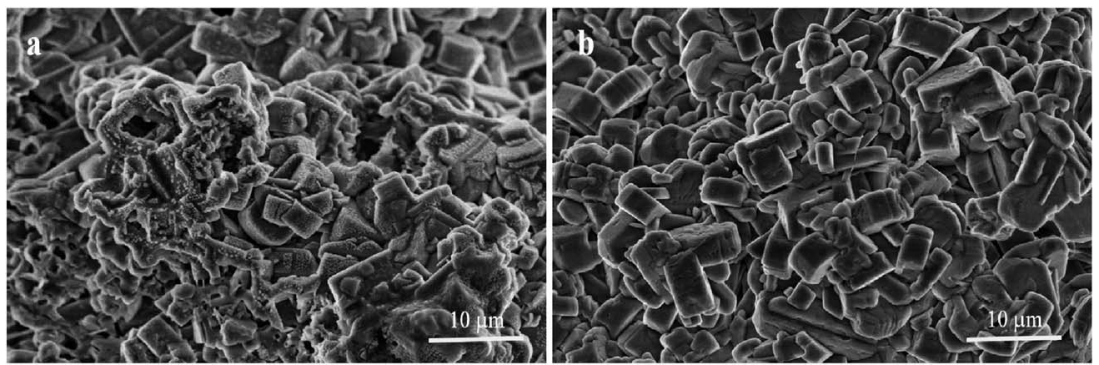

Fig. 8 SEM micrographs of silicalite-1 zeolite membranes after treating with $\mathrm{AcOH} / \mathrm{H}_{2} \mathrm{O}$ mixture for $180 \mathrm{~h}$. (a) Top view for M1 membrane; (b) top view for M2 membrane.

silicalite-1 zeolite layer has complete silanol group network compared to M1 membrane, and thus exhibits higher selectivity for $\mathrm{AcOH} / \mathrm{H}_{2} \mathrm{O}$. At the same time, M1 membrane has a lot of defects, resulting in a part of silicon in the amorphous form. These amorphous silicon components are dissolved under acidic conditions, decreasing the selectivity of M1 membrane when used for a long time.

\section{Conclusion}

In summary, M2 membrane synthesized by hydrothermal synthesis without organic template after support being coated with a mixture of modified cellulose and seed crystals possesses high ideal separation factors of $\mathrm{H}_{2}$ over various gases, being larger than the corresponding Knudsen diffusion coefficients. Moreover, this membrane exhibits higher selectivity for $\mathrm{AcOH}$ from $\mathrm{AcOH} / \mathrm{H}_{2} \mathrm{O}$ mixtures, relative to $\mathrm{M} 1$ membrane. The excellent performance can be attributed to both modified cellulose and the synthesis without organic template. Modified cellulose attracts more of silicalite- 1 nutrients to the support and assists to synthesize more compact silicalite-1 zeolite membrane. No organic template is added during the synthesis process to avoid the calcination after synthesis, thus avoiding macrostructure defects appearing during the calcination process. This study opens a new way to the synthesis of high performance zeolite membranes in the field of separation.

\section{Conflicts of interest}

There are no conflicts to declare.

\section{Acknowledgements}

This study has been supported by the construct program of the key discipline in Hunan province and the Scientific research projects of the education department of Hunan Province (15C0144).

\section{References}

1 R. W. Baker, E. L. Cussler, W. Eykamp, W. J. Koros, R. L. Riley and H. Strathmann, in Membrane separation systems a research and development needs assessment, 1990, pp. Medium: ED.
2 G. E. Romanos, T. A. Steriotis, E. S. Kikkinides, N. K. Kanellopoulos, V. Kasselouri, J. D. F. Ramsay, P. Langlois and S. Kallus, Innovative methods for preparation and testing of $\mathrm{Al}_{2} \mathrm{O}_{3}$ supported silicalite-1 membranes, J. Eur. Ceram. Soc., 2001, 21, 119-126.

3 Y. Yan, M. E. Davis and G. R. Gavalas, Preparation of highly selective zeolite ZSM-5 membranes by a post-synthetic coking treatment, J. Membr. Sci., 1997, 123, 95-103.

4 M. Govindan, B. Zhu, M. Duke, S. Gray and I. S. Moon, $\mathrm{Co}^{3+}$ homogeneous mediator generation efficiency in a divided tubular electrochemical reactor with MFI-type zeolite membrane, J. Ind. Eng. Chem., 2017, 52, 28-34.

5 N. Itoh, J. Ishida, T. Sato and Y. Hasegawa, Vapor phase esterification using a CHA type of zeolite membrane, Catal. Today, 2016, 268, 79-84.

6 Y. Morigami, M. Kondo, J. Abe, H. Kita and K. Okamoto, The first large-scale pervaporation plant using tubular-type module with zeolite NaA membrane, Sep. Purif. Technol., 2001, 25, 251-260.

7 H. Li, J. Xu, J. Wang, J. Yang, K. Bai, J. Lu, Y. Zhang and D. Yin, Seed-free synthesis of highly permeable zeolite NaA membranes through deposition of APTES-functionalized alumina particles on macroporous supports, J. Membr. Sci., 2014, 471, 84-93.

8 J. Shao, Z. Y. Zhan, J. G. Li, Z. B. Wang, K. Li and Y. S. Yan, Zeolite NaA membranes supported on alumina hollow fibers: effect of support resistances on pervaporation performance, J. Membr. Sci., 2014, 451, 10-17.

9 M. Moheb Shahrestani, A. Moheb and M. Ghiaci, High performance dehydration of ethyl acetate/water mixture by pervaporation using NaA zeolite membrane synthesized by vacuum seeding method, Vacuum, 2013, 92, 70-76.

10 A. Huang and J. R. Caro, Cationic Polymer Used to Capture Zeolite Precursor Particles for the Facile Synthesis of Oriented Zeolite LTA Molecular Sieve Membrane, Chem. Mater., 2010, 22, 4353-4355.

11 K. P. Dey, D. Kundu, M. Chatterjee, M. K. Naskar and W. Suchanek, Preparation of NaA Zeolite Membranes Using Poly(Ethyleneimine) as Buffer Layer, and Study of Their Permeation Behavior, J. Am. Ceram. Soc., 2013, 96, 68-72.

12 D. Kunnakorn, T. Rirksomboon, P. Aungkavattana, N. Kuanchertchoo, D. Atong, S. Kulprathipanja and 
S. Wongkasemjit, Performance of sodium A zeolite membranes synthesized via microwave and autoclave techniques for water-ethanol separation: recyclecontinuous pervaporation process, Desalination, 2011, 269, 78-83.

13 Z. L. Cheng, Z. S. Chao, H. Q. Lin and H. L. Wan, NaA zeolite membrane with high performance synthesized by vapor phase transformation method, Chin. J. Chem., 2003, 21, 1430-1432.

14 J. Hedlund, J. Sterte, M. Anthonis, A.-J. Bons, B. Carstensen, N. Corcoran, D. Cox, H. Deckman, W. De Gijnst, P.-P. de Moor, F. Lai, J. McHenry, W. Mortier, J. Reinoso and J. Peters, High-flux MFI membranes, Microporous Mesoporous Mater., 2002, 52, 179-189.

15 M. J. den Exter, H. van Bekkum, C. J. M. Rijn, F. Kapteijn, J. A. Moulijn, H. Schellevis and C. I. N. Beenakker, Stability of Oriented Silicalite-1 Films in View of Zeolite Membrane Preparation, Zeolites, 1997, 19, 13-20.

16 J. Dong, Y. S. Lin, M. Z. C. Hu, R. A. Peascoe and E. A. Payzant, Template-removal-associated microstructural development of porous-ceramic-supported MFI zeolite membranes, Microporous Mesoporous Mater., 2000, 34, 241253.

17 J. Choi, H.-K. Jeong, M. A. Snyder, J. A. Stoeger, R. I. Masel and M. Tsapatsis, Grain boundary defect elimination in a zeolite membrane by rapid thermal processing, Science, 2009, 325, 590-593.

18 X.-L. Wei, S. Liang, Y.-Y. Xu, Y.-L. Sun, J.-F. An and Z.-S. Chao, Methylcellulose-assisted synthesis of a compact and thin NaA zeolite membrane, RSC Adv., 2016, 6, 7186371866.

19 X.-L. Wei, S. Liang, Y.-Y. Xu, Y.-L. Sun, J.-F. An and Z.-S. Chao, Patching NaA zeolite membrane by adding methylcellulose into the synthesis gel, J. Membr. Sci., 2017, 530, 240-249.

20 B. Adnadjević, J. Vukićević, Z. Filipović-Rojka and V. Marković, The influence of NaX zeolite particle size on crystallinity measured by the XRD method, Zeolites, 1990, 10, 699-702.

21 Z. Yang, Y. Liu, C. Yu, X. Gu and N. Xu, Ball-milled NaA zeolite seeds with submicron size for growth of NaA zeolite membranes, J. Membr. Sci., 2012, 392-393, 18-28.

22 D. C. Johnson, M. D. Nicholson and F. C. Haigh, Dimethyl sulfoxide/paraformaldehyde: a nondegrading solvent for cellulose, Eighth Cellulose Conference at Syracuse, New York, May 1975.

23 Y. S. Lin, I. Kumakiri, B. N. Nair and H. Alsyouri, Microporous Inorganic Membranes, Sep. Purif. Rev., 2007, 31, 229-379. 